\title{
Combining jobs and motherhood: is it worse when raising children alone?
}

\section{Roxo', G. Porto' ${ }^{1}$, J. Perelman ${ }^{1,2}$}

${ }^{1}$ NOVA National School of Public Health, Universidade NOVA de Lisboa, 1600-560 Lisbon, Portugal

${ }^{2}$ Public Health Research Centre, NOVA National School of Public Health, Universidade NOVA de Lisboa, 1600-560 Lisbon, Portugal

Address correspondence to Luis Roxo, E-mail:1f.roxo@ensp.unl.pt, luis.filipe.roxo@gmail.com

\begin{abstract}
Background Paid employment has been shown to benefit childless women's health, while employed mothers experience poorer health, and more pronounced fatigue. This study measures the association between job characteristics and the health and well-being of employed mothers and the differential susceptibility to job characteristics between coupled and single-parent mothers.

Methods We used data from the 5th Portuguese National Health Survey from 1649 employed women (aged 25-54) living with a child under 16. We modelled depression (assessed by the Personal Health Questionnaire-8) and self-reported health as a function of job characteristics, adding interaction terms to compare coupled and single-parent mothers, using logistic regressions.

Results Working part-time was associated with depression (odds ratio $(\mathrm{OR})=3.39$, 95\% confidence interval $(\mathrm{Cl})=3.31-3.48)$ and less-than-good health $(\mathrm{OR}=1.28,95 \% \mathrm{Cl}=1.26-1.31)$, compared to working full time. Compared to high-skill jobs, the likelihood for depression among low-skill occupations was lower among coupled mothers $(\mathrm{OR}=0.25,95 \% \mathrm{Cl}=0.24-0.26)$, and higher among single-parent mothers $(\mathrm{OR}=1.75,95 \% \mathrm{Cl}=1.54-1.99)$. Unstable jobs were associated with depression among coupled mothers.

Conclusions Part-time jobs are detrimental for mothers' mental health, but high-skilled jobs are protective for single-parent mothers. Part-time and unstable jobs are linked to poorer self-reported health among coupled mothers. Results question the gendered arrangements that may face employed coupled mothers.
\end{abstract}

Keywords employment, gender, single-parent mothers, part-time, Portugal

\section{Background}

In recent decades women have entered the workforce in growing numbers and in 2017 two-thirds of European women aged 20-64 were employed. ${ }^{1}$ Paid employment may have a positive impact on women's health, ${ }^{2,3}$ but evidence has shown that this positive effect may be limited to childless women, while employed mothers experience poorer health, and more pronounced fatigue. ${ }^{4}$

Some longitudinal evidence on the role expansion theory has shown individual gains from engaging in multiple roles, by developing social and economic resources and stimulating personal growth and satisfaction. ${ }^{5}$ Among women, having a job can aid their economic independence, while increasing their social interactions and self-esteem. ${ }^{6,7}$ Still, the positive effects of multiple roles can be overshadowed by heavy workload and demanding tasks, ${ }^{5}$ and may therefore depend on the job characteristics. Evidence shows that mothers working part-time and in high-status jobs have better health and perform better quality parenting through increased time and reduced family strain. ${ }^{3,4}$ Employed mothers may achieve greater life satisfaction by taking more complex jobs, as work can provide a sense of fulfilment and family life can adapt to time-consuming work. ${ }^{8}$ Nevertheless, the health of employed mothers may be affected by jobs with greater schedule flexibility, as their gendered responsibility for parenting and domestic labour is reinforced, ${ }^{9}$ especially for those living with a partner. ${ }^{10}$

To the best of our knowledge, evidence is scarce about the way job characteristics affect differently single-parent mothers (those without a resident partner, hereinafter 'lone mothers'), and those married or in a de facto parenting relationship (hereinafter 'coupled mothers'), despite the documented health

Roxo L., Doctoral Candidate.

Porto G., Masters Candidate.

Perelman J., Associate Professor. 
inequalities between these two groups. ${ }^{11}$ Most research has studied inequalities between coupled and lone mothers focusing on unequal patterns of exposure to health risks, while the differential susceptibilities to those risks have rarely been evaluated. ${ }^{11,12}$ It is known that lone-mother families are a vulnerable population, more prone to experience economic disadvantages $^{13,14}$ and poor working conditions (part-time, low-paid or low-skill jobs, casual employment and job insecurity). ${ }^{11,14}$ It is thus expected that lone mothers experience those conditions with a greater difficulty, leading to poorer health.

Work-family conflict is common among lone mothers, who may struggle with the disappointment of their expectations as good mothers, difficulties in child-care arrangements, and the absence of a partner to share responsibilities with. ${ }^{11}$ Conversely, resource gains may have a greater impact among lone mothers. ${ }^{3,11}$ Although employment has been showed to improve their mental health, ${ }^{15}$ we can expect that a more complex job can positively affect their well-being, in the absence of a partner.

In Portugal, gender differences in paid working time are small, ${ }^{16}$ and $82.3 \%$ of women with children under 6 are employed. ${ }^{17}$ Still, and unlike the case in more egalitarian countries, performance of unpaid work remains uneven. ${ }^{16,18}$ Traditional gender roles persist in which men remain the breadwinners while women ensure the housework and the family well-being. ${ }^{18}$ Also, organizations still value workers without family responsibilities; a worker who needs to provide family support must usually come to an informal arrangement with her supervisors in the absence of formal human resources policies. ${ }^{18}$ Hence, the rates of work and family stress are higher among Portuguese women with children than in most European countries. ${ }^{18}$

This study measures the association between job characteristics and health and well-being among Portuguese employed mothers and compares this association between coupled and lone mothers. By using a sample of Portuguese mothers, we address this issue in a country where women face gendered expectations in both work and family contexts. By analysing lone and coupled mothers separately, we overcome the study of overrepresentation of lone mothers in precarious and lowpaid jobs, to provide information about differential susceptibility to job characteristics.

\section{Methods}

\section{Data}

Data were derived from the 2014 Portuguese National Health Survey (NHS), a community-based cross-sectional survey $(N=18$ 204), using a multi-stage stratified probabilistic sampling to achieve a representative sample of non-institutionalized people living in Portugal. ${ }^{19}$ Following recommendations from the European Health Interview Survey ${ }^{20}$ it aims to characterize the health status, health care and health determinants of the Portuguese population, through face-to-face questionnaires. To adjust for nonresponse, we used the sample weights provided with the database.

We selected all employed women aged 25-54 living with at least one child younger than 16 years. We excluded some observations $(n=22)$ due to missing or inconsistent data regarding family composition. The final sample was composed of 1649 women. Among these women, we considered 'lone mothers' $(n=320)$ to be those who were single, divorced or widowed, and not living with a partner. Married women and those living in a non-marital partnership were considered 'coupled mothers' $(n=1329)$.

\section{Dependent variables}

Depression was assessed by the Personal Health Questionnaire (PHQ-8) Depression Scale. In this scale, participants were asked eight questions about the frequency of depressive symptoms (e.g. 'Feeling down, depressed, or hopeless') over the previous 2 weeks. Response categories include 'Not at all' (0), 'Several days' (1), 'More than half the days' (2), and 'Nearly every day' (3). A final score was obtained from the sum of the scores of each item, ranging from 0 to 24 . In this study a cutoff of 10 was used to define depression. This cutoff has been proven a reliable measure ${ }^{21}$ of depression in the general population.

Self-reported health (SRH) was assessed by the question 'How is your health in general?' This question has been widely used in research as a consistent measure of general health. ${ }^{13}$ Considering the low number of cases in extreme categories, this variable was recoded as a binary variable with a value ' 1 ' attributed to less-than-good SRH ('Reasonable', 'Bad' or 'Very bad'), and zero otherwise.

\section{Explanatory variables}

We used three job characteristics as explanatory variables: part-time versus full-time job, occupational status and unstable job situation. The occupational status was defined by recoding the self-reported occupation into four levels (based on the International Standard Classification of Occupations 2008, ISCO-08): High (specialized tasks involving complex thinking skills), Medium-high (technical and practical tasks with some complexity), Medium (machinery operation or electronic equipment handling) and Low (simple or routine performance of manual tasks). ${ }^{22}$ Unstable job situation 
was defined as having a temporary contract or being selfemployed, as opposed to having a permanent job with a work contract of unlimited duration.

\section{Covariates}

Age was stratified in three groups (25-34, 35-44, 45-54). Family characterization was assessed by two variables: children living at home younger than 5 years old ( 0 or at least 1 ) and number of children living at home between 5 and 15 years of age $(0,1$ or more than 1$)$.

Socioeconomic status (SES) was assessed by educational level (lower than secondary, secondary and tertiary education) and household income quintile (as available on the database).

Social support was measured by the Oslo Social Support Scale (OSSS-3), a brief 3-item tool assessing the number of close and trustable people (from 'None' to ' 6 or more'), interest and concern from others (from 'A lot' to 'None'), and support from neighbours (from 'Very easy' to 'Very difficult'). The sum of these items provides a score between 3 and 14 that was used to classify social support as poor (3-8), moderate (9-11) or strong (12-14). ${ }^{23}$

\section{Statistical analysis}

Descriptive statistics were used to characterize our sample. Chi-square and Fisher's Exact Test were used to compare lone and coupled mothers in all our variables.

We modelled the logit of outcomes $\mathrm{Y}$ (depression and less-than-good SRH) as function of the job characteristics (Model 1).

\section{Model 1}

$$
\begin{aligned}
\log \left(\frac{Y_{i}}{1-Y_{i}}\right)= & e B_{0}+\beta_{1} \text { PartTime }_{i}+\beta_{2} \text { OccupationalStatus }_{i} \\
& +\beta_{3} \text { Instability }_{i}+\beta_{4} \text { SES }_{i}+\beta_{5} \text { Family }_{i} \\
& +\beta_{6} \text { SocialSupport }_{i}+\beta_{7} \text { LoneMother }_{i}
\end{aligned}
$$

Then, we tested the interaction between explanatory variables and lone-mother status, to assess the differential susceptibility to job characteristics for lone and coupled mothers (Model 2). From the models, separate odds ratio (OR) were obtained for these two groups, through the exponentiated sum of coefficients for the variable and its interaction. Confidence intervals $(95 \% \mathrm{CI})$ were obtained by changing the reference categories of the regression models. $^{24}$
Model 2

$$
\begin{aligned}
\log \left(\frac{Y_{i}}{1-Y_{i}}\right)= & e B_{0}+\beta_{1} \text { PartTime }_{i}+\beta_{2} \text { OccupationalStatus }_{i} \\
& +\beta_{3} \text { Instability }_{i}+\beta_{4} \text { SES }_{i}+\beta_{5} \text { Family }_{i} \\
& +\beta_{6} \text { SocialSupport }_{i}+\beta_{7} \text { LoneMother }_{i} \\
& +\beta_{8}\left(\text { PartTime } \times \text { LoneMother }_{i}\right. \\
& +\beta_{9}\left({\text { OccupationalStatus } \times \text { LoneMother })_{i}}\right. \\
& +\beta_{10}(\text { Instability } \times \text { LoneMother })_{i}
\end{aligned}
$$

All models were adjusted for SES, family characterization, social support, and lone-mother status. Earlier research has highlighted the relevance of these variables explaining difficulties in the work-family interface and vulnerabilities of lone mothers. $3,4,25,26$

Statistical analyses were performed using SPSS v24 software. $^{27}$

\section{Ethics}

Authorization to use data from the NHS 2014 was obtained. No ethics approval was required since this study uses secondary data from an official database, which was provided to researchers after anonymization and recoding to avoid any possible identification (e.g. the grouping of income into quintiles, the removal of the birthdate, etc.).

\section{Results}

Most mothers were aged between 35 and 44 years old (54.1\%) (Table 1). More than one-third (35.4\%) had lower than secondary education. Compared to coupled mothers, lone mothers were significantly more represented among the poorest income quintile (18\% against $9.5 \%$ ) and less represented in the wealthiest one $(15.5 \%$ against $27.6 \%)$. Poor social support was more common amongst coupled mothers $(12.9 \%)$ than lone mothers $(8.5 \%)$. Lone mothers more frequently worked parttime $(11.1 \%)$ and had an unstable job situation (25.4\%). The percentage of women working in low-skilled jobs was higher among lone mothers (18.4\%) than coupled mothers (13.6\%), who more often had high occupational status $(34.2 \%)$.

Depression was significantly more common among coupled mothers (8.1\%). Prevalence of depression was higher (Fig. 1) among part-time than among full-time employees, both among coupled (20.0\% and $7.3 \%$, respectively) and lone mothers (14.9\% and $4.2 \%)$. Among lone mothers, prevalence of depression was higher among those in low- $(7.1 \%)$ and 
Table 1 Characterization of the sample, by lone-mother status

\begin{tabular}{|c|c|c|c|c|c|c|c|}
\hline & \multicolumn{2}{|c|}{ Overall } & \multicolumn{2}{|c|}{$\begin{array}{l}\text { Coupled mothers } \\
(87.5 \%)\end{array}$} & \multicolumn{2}{|c|}{$\begin{array}{l}\text { Lone mothers } \\
(12.5 \%)\end{array}$} & \multirow[t]{2}{*}{$P$-value } \\
\hline & $n^{\mathrm{a}}$ & $\%$ & $n^{\mathrm{a}}$ & $\%$ & $n^{\mathrm{a}}$ & $\%$ & \\
\hline \multicolumn{8}{|l|}{ Characterization variables } \\
\hline \multicolumn{8}{|l|}{ Age groups $^{b}$} \\
\hline $25-34$ & 402 & 26.9 & 336 & 26.7 & 66 & 27.9 & \multirow[t]{3}{*}{$<0.001$} \\
\hline $35-44$ & 933 & 54.1 & 753 & 54.4 & 180 & 52.7 & \\
\hline $45-54$ & 314 & 19.0 & 240 & 18.9 & 74 & 19.4 & \\
\hline \multicolumn{8}{|l|}{ Educational level $^{\mathrm{b}}$} \\
\hline Lower than secondary education & 602 & 35.4 & 477 & 35.5 & 125 & 34.8 & \multirow[t]{3}{*}{$<0.001$} \\
\hline Secondary or post-secondary education & 468 & 28.2 & 384 & 28.2 & 84 & 28.2 & \\
\hline Tertiary education & 579 & 36.4 & 468 & 36.3 & 111 & 37.0 & \\
\hline \multicolumn{8}{|l|}{ Income $e^{b}$} \\
\hline First quintile & 225 & 10.5 & 164 & 9.5 & 61 & 18.0 & \multirow[t]{5}{*}{$<0.001$} \\
\hline Second quintile & 285 & 16.1 & 198 & 14.7 & 87 & 25.5 & \\
\hline Third quintile & 352 & 23.2 & 288 & 23.1 & 64 & 23.6 & \\
\hline Forth quintile & 399 & 24.1 & 329 & 25.1 & 70 & 17.4 & \\
\hline Fifth quintile & 388 & 26.1 & 350 & 27.6 & 38 & 15.5 & \\
\hline \multicolumn{8}{|l|}{ Number of children under 5 years old ${ }^{b}$} \\
\hline 0 & 1081 & 63.6 & 831 & 61.3 & 250 & 79.7 & \multirow[t]{2}{*}{$<0.001$} \\
\hline 1 or more & 568 & 36.4 & 498 & 38.7 & 70 & 20.3 & \\
\hline \multicolumn{8}{|c|}{ Number of children between 5 and 15 years old ${ }^{b}$} \\
\hline 0 & 318 & 23.4 & 277 & 24.8 & 41 & 14.3 & \multirow[t]{3}{*}{$<0.001$} \\
\hline 1 & 960 & 55.2 & 735 & 53.0 & 225 & 70.1 & \\
\hline$>1$ & 371 & 21.4 & 317 & 22.2 & 54 & 15.6 & \\
\hline \multicolumn{8}{|l|}{ Social support ${ }^{c, d}$} \\
\hline Poor & 171 & 12.3 & 133 & 12.9 & 38 & 8.5 & \multirow[t]{3}{*}{$<0.001$} \\
\hline Moderate & 917 & 53.5 & 732 & 52.9 & 185 & 57.6 & \\
\hline Strong & 540 & 34.2 & 446 & 34.2 & 94 & 33.9 & \\
\hline \multicolumn{8}{|l|}{ Job characteristics } \\
\hline Part-time ${ }^{b}$ & 101 & 7.1 & 82 & 6.5 & 19 & 11.1 & $<0.001$ \\
\hline \multicolumn{8}{|l|}{ Occupational status ${ }^{\mathrm{e}}$} \\
\hline High & 509 & 33.6 & 415 & 34.2 & 94 & 30.0 & \multirow[t]{4}{*}{$<0.001$} \\
\hline Medium-high & 189 & 10.6 & 156 & 10.5 & 33 & 10.5 & \\
\hline Medium & 650 & 41.6 & 519 & 41.7 & 131 & 41.1 & \\
\hline Low & 261 & 14.2 & 204 & 13.6 & 57 & 18.4 & \\
\hline Unstable job situation ${ }^{b}$ & 370 & 22.8 & 290 & 22.4 & 80 & 25.4 & $<0.001$ \\
\hline \multicolumn{8}{|l|}{ Health and well-being } \\
\hline Depression $^{f}$ & 103 & 7.8 & 80 & 8.1 & 23 & 5.4 & $<0.001$ \\
\hline Less-than-good self-reported health ${ }^{\dagger}$ & 530 & 32.0 & 429 & 32.2 & 101 & 30.0 & $<0.001$ \\
\hline
\end{tabular}

aUnweighted frequencies.

${ }^{\mathrm{b}} n=1649$.

'Oslo Social Support Scale.

${ }^{d} n=1628$.

$e e_{n}=1609$.

${ }^{\mathrm{f}} n=1631$.

Bold results indicate statistically significant results $(P<0.05)$. 


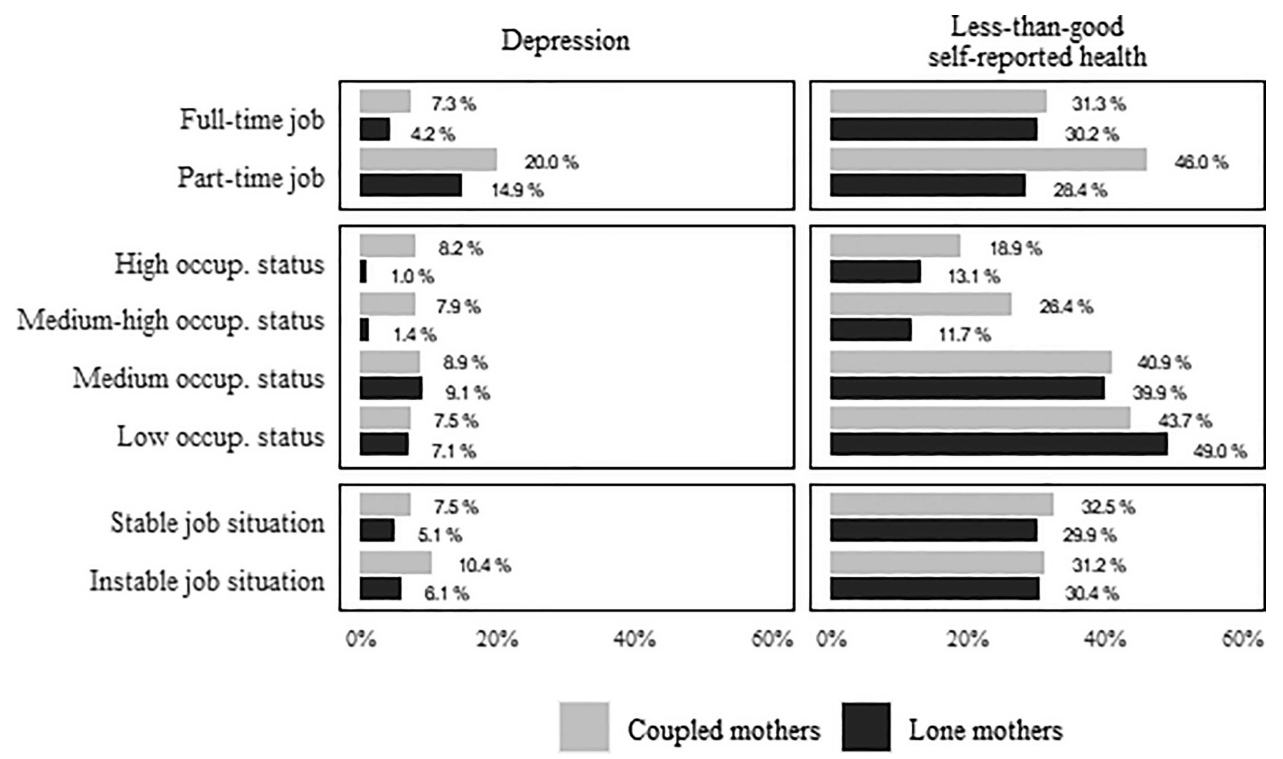

Fig. 1 Prevalence (\%) of depression and less-than-good self-reported health by employment characteristics, among lone and coupled mothers.

medium-skilled jobs $(9.1 \%)$ than among those in mediumhigh $(1.4 \%)$ or high occupational status $(1.0 \%)$.

Prevalence of less-than-good SRH was 32.2\% among lone mothers and $30.0 \%$ among coupled mothers. Among coupled mothers prevalence of less-than-good SRH was higher among those working part-time $(46.0 \%)$ than among those with full-time jobs $(31.3 \%)$. Half of lone mothers $(49.0 \%)$ with low-skilled jobs reported less-than-good health, compared to $13.1 \%$ among those with high occupational status.

Adjusted models show the likelihood of feeling depressed to be 3.39 times greater in mothers who work part-time (Table 2), compared to those working full time. These OR were higher among lone $(\mathrm{OR}=4.51,95 \% \mathrm{CI}=4.22-4.81)$ than among coupled mothers $(\mathrm{OR}=3.34,95 \% \mathrm{CI}=3.25$ 3.43) (Table 3). Compared to high-skill jobs, the OR for depression were lower among coupled mothers with mediumhigh $(\mathrm{OR}=0.42,95 \% \mathrm{CI}=0.41-0.44)$, medium $(\mathrm{OR}=0.41$, $95 \% \mathrm{CI}=0.40-0.42)$, or low-skill jobs $(\mathrm{OR}=0.25$, $95 \% \mathrm{CI}=0.24-0.26)$. On the contrary, lone mothers with low $(\mathrm{OR}=1.75,95 \% \mathrm{CI}=1.54-1.99)$ or medium skill jobs $(\mathrm{OR}=3.50,95 \% \mathrm{CI}=3.11-3.93)$ were more likely to be depressed, compared to those with high occupational status. Having an unstable job situation (as opposed to a permanent job) was associated with higher likelihood of depression, but only among coupled mothers $(\mathrm{OR}=1.09,95 \% \mathrm{CI}=1.07-$ 1.11).

The likelihood for less-than-good SRH were 1.28 higher among those working part-time (Table 2), compared to those working full time. Mothers working in medium- $(\mathrm{OR}=1.45$, $95 \% \mathrm{CI}=1.42-1.47)$ or low-skilled jobs $(\mathrm{OR}=1.32$, $95 \% \mathrm{CI}=1.30-1.35)$ were more likely to report less-than- good health than those with high occupational status. Having a part-time job (as opposed to a full-time job) increased the likelihood for coupled mothers $(\mathrm{OR}=1.46,95 \% \mathrm{CI}=1.43$ $1.50)$, while decreasing them for lone mothers $(\mathrm{OR}=0.82$, $95 \% \mathrm{CI}=0.78-0.86$ ) (Table 3).

\section{Discussion}

\section{Main findings of the study}

The results of this study show that employed mothers' health and well-being vary with job characteristics and that coupled and lone mothers are not equally susceptible to these characteristics. We may summarize our results along three dimensions: (i) part-time jobs are linked to both coupled and lone mothers' depressive symptoms, but to a better SRH among lone mothers; (ii) more complex jobs are associated with depression among coupled mothers, but are protective for lone mothers' mental health and SRH; (iii) job instability is not meaningfully associated with mothers' SRH.

\section{What is already known on this topic and what this study adds}

First, mothers working part-time were more likely to be depressed, compared to those working full time. This is inconsistent with earlier research reporting a relationship between part-time work and mother's better health, ${ }^{6,28}$ and work-family functioning. ${ }^{29}$ A possible explanation has to do with the particular stressors faced by part-time workers, namely the poor working conditions, limited advancement opportunities, unfulfilled productivity expectations, few employment benefits and stigma. ${ }^{28,30}$ These results may 
Table 2 Association (OR and 95\% Cl) between job characteristics and depression/less-than-good self-reported health (SRH) (Model 1)*

\begin{tabular}{|c|c|c|c|c|}
\hline & & $\beta$ & P-value & $O R(95 \% \mathrm{Cl})$ \\
\hline \multirow[t]{8}{*}{ A_Depression } & Full-time job & 0 & - & 1.00 \\
\hline & Part-time job & 1.22 & $<0.001$ & $3.39(3.31-3.48)$ \\
\hline & High occupational status & 0 & - & 1.00 \\
\hline & Medium-high status & -0.86 & $<0.001$ & $0.42(0.41-0.44)$ \\
\hline & Medium status & -0.78 & $<0.001$ & $0.46(0.45-0.47)$ \\
\hline & Low status & -1.29 & $<0.001$ & $0.28(0.27-0.28)$ \\
\hline & Stable job situation & 0 & - & 1.00 \\
\hline & Unstable job situation & 0.08 & $<0.001$ & $1.09(1.07-1.11)$ \\
\hline \multirow[t]{8}{*}{ B_-Less-than-good SRH } & Full-time job & 0 & $<0.001$ & 1.00 \\
\hline & Part-time job & 0.25 & & $1.28(1.26-1.31)$ \\
\hline & High occupational status & 0 & - & 1.00 \\
\hline & Medium-high status & -0.10 & $<0.001$ & $0.91(0.89-0.93)$ \\
\hline & Medium status & 0.37 & $<0.001$ & $1.45(1.42-1.47)$ \\
\hline & Low status & 0.28 & $<0.001$ & $1.32(1.30-1.35)$ \\
\hline & Stable job situation & 0 & - & 1.00 \\
\hline & Unstable job situation & -0.04 & $<0.001$ & $0.97(0.95-0.98)$ \\
\hline
\end{tabular}

*All values were obtained from Model 1, so that results are adjusted for age groups, socioeconomic status, family characterization, social support and lone-mother status

also be related to a low-wage effect not captured by income quintiles, which may imperfectly measure the financial conditions. Note that Portugal is amongst the OECD countries with the lowest wages, ${ }^{31}$ meaning that working part-time may imply extremely difficult living conditions. Even at home, despite having more time for their child(ren), having a part-time job may be stressful and/or associated with complicated child-care arrangements, unfulfilled expectations from these women and their families and gendered division of housework. ${ }^{9,30}$ Similar factors may also explain the fact that depression was more likely among women with unstable jobs, ${ }^{32}$ which may be affected by the difficulties of achieving the desired life pattern due to precariousness. ${ }^{32}$ However, this effect was significant only among coupled mothers, and lone mothers even reported a better SRH when working part-time. As lone mothers more commonly experience unemployment, transitioning towards a paid job, even a temporary one, may help to reduce levels of stress. ${ }^{15}$

Second, coupled mothers in more complex (above lowskilled) jobs were more likely to be depressed. Although high occupational status seems to be associated with greater flexibility, ${ }^{33}$ this may be used to reinforce traditional gender roles, ${ }^{9}$ as often women add to their demanding jobs the responsibility of managing their households. ${ }^{10}$ The career prospects for employed mothers in high-skill jobs may be affected by the persistent segregation of the labour market ${ }^{34}$ and discrimination (e.g. exclusion from leadership, constant need to prove their competence). ${ }^{35}$ Psychosocial mechanisms may affect these women's health through unfulfilled expectations of an equal society, despite some advancement in the job market. ${ }^{36}$ These factors may overshadow the positive health impact of a job with a higher occupational status, which increase women's opportunities for scheduling flexibility and stimulating and cognitively rewarding work. ${ }^{3}$ On the contrary, having a highskilled job seems protective for lone mothers' mental health. The benefits brought by these jobs intersect some of the resources that more advantaged women already enjoy, ${ }^{3}$ having a more significant positive impact among women in vulnerable situations. For a lone mother, achieving and maintaining a demanding job may also provide personal satisfaction and help to heal past traumas such as divorce or widowing. These more complex jobs also protect mothers' perceived health, with a greater protective effect among lone mothers. This can be due to the greater burden of occupational diseases among low-differentiated workers, who are exposed to a considerable range of risk factors undermining their capacity for 
Table 3 Association (OR and 95\% Cl) between job characteristics and depression/less-than-good self-reported health (SRH), by lone-mother status (Model 2)

\begin{tabular}{|c|c|c|c|c|c|}
\hline & & $\beta$ & P-value & $\begin{array}{l}\text { OR }(95 \% \mathrm{Cl}) \text { for } \\
\text { coupled mothers }\end{array}$ & $\begin{array}{l}\text { OR }(95 \% \mathrm{Cl}) \text { for lone } \\
\text { mothers }\end{array}$ \\
\hline \multirow[t]{11}{*}{ A_Depression } & Lone mother (ref: coupled mother) & -2.21 & $<0.001$ & & \\
\hline & Part-time job (ref: full-time job) & 1.21 & $<0.001$ & $3.34(3.25-3.43)$ & $4.51(4.22-4.81)$ \\
\hline & Part-time*Lone mother & 0.30 & $<0.001$ & & \\
\hline & Medium-high status (ref: high) & -0.86 & $<0.001$ & $0.42(0.41-0.44)$ & $0.53(0.43-0.64)$ \\
\hline & Medium status (ref: high) & -0.89 & $<0.001$ & $0.41(0.40-0.42)$ & $3.50(3.11-3.93)$ \\
\hline & Low status (ref: high) & -1.38 & $<0.001$ & $0.25(0.24-0.26)$ & $1.75(1.54-1.99)$ \\
\hline & Medium-high status*Lone mother & 0.21 & 0.036 & & \\
\hline & Medium status*Lone mother & 2.14 & $<0.001$ & & \\
\hline & Low status*Lone mother & 1.94 & $<0.001$ & & \\
\hline & Unstable job situation (ref: stable) & 0.09 & $<0.001$ & $1.09(1.07-1.12)$ & $0.90(0.85-0.96)$ \\
\hline & Unstable job situation $*$ Lone mother & -0.19 & $<0.001$ & & \\
\hline \multirow[t]{11}{*}{ B-Less-than-good SRH } & Lone mother (ref: coupled mother) & -0.36 & $<0.001$ & & \\
\hline & Part-time job (ref: full-time job) & 0.38 & 0.001 & $1.46(1.43-1.50)$ & $0.82(0.78-0.86)$ \\
\hline & Part-time* Lone mother & -0.58 & $<0.001$ & & \\
\hline & Medium-high status (ref: high) & -0.06 & $<0.001$ & $0.94(0.92-0.97)$ & $0.64(0.60-0.69)$ \\
\hline & Medium status (ref: high) & 0.35 & $<0.001$ & $1.42(1.40-1.45)$ & $1.71(1.64-1.78)$ \\
\hline & Low status (ref: high) & 0.17 & $<0.001$ & $1.19(1.16-1.22)$ & $2.33(2.23-2.45)$ \\
\hline & Medium-high status*Lone mother & -0.38 & $<0.001$ & & \\
\hline & Medium status*Lone mother & 0.19 & $<0.001$ & & \\
\hline & Low status*Lone mother & 0.67 & $<0.001$ & & \\
\hline & Unstable job situation (ref: stable) & -0.05 & $<0.001$ & $0.95(0.94-0.96)$ & $0.98(0.94-1.01)$ \\
\hline & Unstable job situation $*$ Lone mother & 0.03 & 0.118 & & \\
\hline
\end{tabular}

Odds ratio by lone-mother status, for each explanatory variable (versus the reference category), were calculated by taking the exponential of the simple effect coefficients summed to the interaction terms coefficient (e.g. coupled mothers working part-time are 3.34 times more likely to be depressed than coupled mothers in full-time jobs).

All results are adjusted for age groups, socioeconomic status, family characterization and social support.

work. ${ }^{37}$ Given that lone mothers often work in poorer jobs, they are likely to be more affected by the impact of these low-skilled jobs (while benefiting from high occupational status).

Finally, our results show that job instability does not affect mothers' SRH in a meaningful way (with only a slight decrease of the OR among coupled mothers). This is inconsistent with studies disclosing the prejudicial health effects of temporary jobs. ${ }^{32}$ Other research has shown that job insecurity (the concern about the future existence of the job) impacts people with both permanent and temporary contracts. ${ }^{38}$ In our study differences may be small because our sample is composed only of working mothers, who often have a history of career interruptions and job precariousness, and may thus fear the loss of their job even if they have a permanent contract. Earlier research has found that among women temporary contracts are associated with poorer mental health but not with poorer SRH. ${ }^{39}$ 


\section{Limitations and strengths of this study}

In this study we used data from a NHS with a representative sample of the Portuguese population. However, by using cross-sectional data we were not able to exclude social selection, as women with poor health may have greater difficulty in maintaining a stable and complex job. As we includedss only employed women, we can expect our sample to be healthier than those unable to find a job.

All of our data were self-reported, and no data about family arrangements were available. Future studies may enrich our results, for instance, by including data about child custody and fathers' participation in children's education (among lone mothers) and division of parenting and household tasks (among coupled mothers).

Finally, the study was performed on a sample of the Portuguese population, so that findings may not be generalizable to other settings. Portugal is characterized by high rates of women's participation in the labour market but is marked by traditional gendered family arrangements. In this sense, this study provides evidence that may be applied to countries with similar gendered patterns of paid/unpaid work (such as Cyprus, Bulgaria or Lithuania). ${ }^{16}$ Also, Portugal is an interesting context in which to study the relationship between societal gender roles and women's health, providing information about the challenges that employed women with children may face in other Southern European countries in which family functioning follows a traditional pattern (despite lower women's participation in the labour market).

\section{Conclusion}

This study assessed the association between job characteristics and the health and well-being of women combining paid jobs and motherhood. Part-time, unstable and demanding jobs are detrimental for mothers' mental health, but highskilled jobs are protective when women are not in a couple relationship. Part-time and unstable jobs are linked to a high risk of poor SRH, but exclusively among mothers in couples; high-skilled jobs are linked to a better health among coupled and lone mothers. Results confirm the negative effects of precarious jobs for health and well-being and the positive effect of complex jobs for lone mothers, while questioning the gendered arrangements that may render mothers in couple relationships more vulnerable to high-skilled jobs.

\section{Acknowledgements}

The authors thank Gabriela Corá and Teresa Veloso for their support in the initial phases of this study. This work was supported by a Doctoral fellowship provided by the
Portuguese Foundation for Science and Technology - FCT [PD/BD/135591/2018] to LR.

\section{Funding}

This work was supported by a Doctoral fellowship provided by the Portuguese Foundation for Science and Technology FCT [PD/BD/135591/2018] to LR.

\section{Conflicts of interest}

None declared.

\section{References}

1 European Commission. 2018 Report on equality between women and men in the EU. Luxembourg: Publications Office of the European Union, 2018, Available from: https://ec.europa.eu/newsroom/just/docume nt.cfm?doc_id $=50074$.

2 Kostiainen E, Martelin T, Kestilä L et al. Employee, partner, and mother: women's three roles and their implications for health. J Fam Issues 2009;30(8):1122-50.

3 Augustine JM. Mothers employment, education, and parenting. Work Ocсир 2014;41(2):237-70.

4 Floderus B, Hagman M, Aronsson G et al. Work status, work hours and health in women with and without children. Occup Environ Med 2009;66(10):704-10.

5 Nordenmark M. Multiple social roles and well-being: a longitudinal test of the role stress theory and the role expansion theory. Acta Sociol 2004;47(2):115-26.

6 von der Lippe E, Rattay P. Association of partner, parental, and employment statuses with self-rated health among German women and men. SSM - Popul Health 2016;2:390-8

7 Backhans MC, Lundberg M, Månsdotter A. Does increased gender equality lead to a convergence of health outcomes for men and women? A study of Swedish municipalities. Soc Sci Med 2007;64(9):1892-903

8 Blair-Loy M. Competing devotions. Career and family among women executives. Cambridge, Massachusetts, and London: Press HU, 2003.

9 Drago R. What would they do? Childcare under parental leave and reduced hours options. Ind Relations A J Econ Soc 2011;50(4):610-28.

10 Sümer S, Smithson J, Guerreiro MD et al. Becoming working mothers: reconciling work and family at three particular workplaces in Norway, the UK, and Portugal. Community Work Fam 2008;11(4):365-84.

11 Robinson LD, Magee CA, Caputi P. Sole mothers in the workforce: a systematic review and agenda for future work-family research. J Fam Theory Rev 2018;10(1):280-303.

12 Diderichsen F, Evans T, Whitehead M. The social basis of disparities in health. In: Challenging Inequities in Health - From Ethics to Action. New York: Oxford University Press, 2001, 37-43.

13 Rousou E, Kouta C, Middleton N et al. Single mothers' self-assessment of health: a systematic exploration of the literature. Int Nurs Rev 2013;60(4):425-34. 
14 Broussard CA. Research regarding low-income single mothers' mental and physical health: a decade in review. J Poverty 2010;14(4):443-51.

15 Harkness S. The effect of employment on the mental health of lone mothers in the UK before and after new labour's welfare reforms. Soc Indic Res 2016;128:763-91.

16 Eurofound. Striking a Balance: Reconciling Work and Life in the EU. Luxembourg: Publications Office of the European Union, 2018, Available from: https://www.eurofound.europa.eu/sites/default/files/ef_ publication/field_ef_document/ef18065en.pdf.

17 European Union. Employment and Social Developments in Europe. Sustainable Growth for All: Choices for the Future of Social Europe. Luxembourg: Publications Office of the European Union, 2019, Available from: https://op.europa.eu/pt/publication-detail/-/publicatio n/747fefa1-d085-11e9-b4bf-01aa75ed71a1/language-en.

18 Matias M, Andrade C, Fontaine AM. The interplay of gender, work and family in Portuguese families. Work Organ Labour Glob 2012;6(1):11-26.

19 Statistics Portugal. Inquérito Nacional de Saúde: Documento Metodológico. Statistics Portugal, 2014. Available from: www.ine.pt.

20 Eurostat. European Health Interview Survey (EHIS Wave 2) Ethodological Manual. Luxembourg: Publications Office of the European Union, 2013, Available from: https://ec.europa.eu/ eurostat/documents/3859598/5926729/KS-RA-13-018-EN.PDF/ 26c7ea80-01d8-420e-bdc6-e9d5f6578e7c.

21 Kroenke K, Strine TW, Spitzer RL et al. The PHQ-8 as a measure of current depression in the general population. I Affect Disord 2009;114(1-3):163-73.

22 International Labour Organization. International Standard Classification of Occupations (ISCO-08). Structure, Group Definitions and Correspondence Tables. Geneve: International Labour Office, 2012, Available from: https://www.ilo.org/wcmsp5/groups/public/---dgrepo rts/---dcomm/---publ/documents/publication/wcms_172572.pdf.

23 Bøen H, Dalgard OS, Bjertness E. The importance of social support in the associations between psychological distress and somatic health problems and socio-economic factors among older adults living at home: a cross sectional study. BMC Geriatr 2012;12:27.

24 Figueiras A, Domenech-Massons JM, Cadarso C. Regression models: calculating the confidence interval of effects in the presence of interactions. Stat Med 1998;17(18):2099-105.

25 Cairney J, Boyle M, Offord DR et al. Stress, social support and depression in single and married mothers. Soc Psychiatry Psychiatr Epidemiol 2003;38(8):442-9.
26 Manuel JI, Martinson ML, Bledsoe-Mansori SE et al. The influence of stress and social support on depressive symptoms in mothers with young children. Soc Sci Med 2012;75(11):2013-20.

27 IBM Corp. IBM SPSS Statistics for Windows, Version 24.0. NY: IBM Corp, 2016.

28 Bartoll X, Cortès I, Artazcoz L. Full- and part-time work: gender and welfare-type differences in European working conditions, job satisfaction, health status, and psychosocial issues. Scand J Work Environ Health 2014;40(4):370-9.

29 Buehler C, O’Brien M. Mothers' part-time employment: associations with mother and family well-being. J Fam Psychol 2011;25(6): 895-906.

30 Higgins C, Duxbury L, Johnson KL. Part-time work for women: does it really help balance work and family? Hum Resour Manage 2000;39(1):17-32.

31 OECD. Average wages (indicator). Available from: https://data.oe cd.org/earnwage/average-wages.htm (23 November 2020, last date accessed).

32 Pirani E, Salvini S. Is temporary employment damaging to health? A longitudinal study on Italian workers. Soc Sci Med 2015;124: $121-31$.

33 Kossek EE, Lautsch BA. Work-life flexibility for whom? Occupational status and work-life inequality in upper, middle, and lower level jobs. Acad Manag Ann 2018;12(1):5-36.

34 Gonäs L, Wikman A, Vaez M et al. Changes in the gender segregation of occupations in Sweden between 2003 and 2011. Scand J Public Health 2019;47(3):344-7.

35 Halley MC, Rustagi AS, Torres JS et al. Physician mothers' experience of workplace discrimination: a qualitative analysis. BMJ 2018;363:k4926.

36 Olafsdottir S. Gendered health inequalities in mental well-being? The Nordic countries in a comparative perspective. Scand J Public Health 2017;45(2):185-94.

37 van der Molen H, de Vries S, Sluiter JK. Occupational diseases among workers in lower and higher socioeconomic positions. Int J Environ Res Public Health 2018;15(12):2849.

38 Virtanen P, Janlert U, Hammarstrom A. Exposure to temporary employment and job insecurity: a longitudinal study of the health effects. Occup Environ Med 2011;68(8):570-4.

39 Virtanen P, Vahtera J, Kivimäki $\mathrm{M}$ et al. Employment security and health. J Epidemiol Community Health 2002;56(8): $569-74$. 